\title{
O ensino-aprendizagem online de Bioquímica e as ferramentas de mediação: um estudo de caso
}

\section{The online teaching and learning of Biochemistry and the mediation tools: a case study}

\author{
Adriana Oliveira Ferreira ${ }^{1}$, Clauciene Aparecida Lima1 ${ }^{1}$ Gabriel Gerber Hornink ${ }^{1^{*}}$ \\ *e-mail: gabriel.hornink@unifal-mg.edu.br \\ ${ }^{1}$ Laboratório de Mídias Educacionais, Departamento de Bioquímica, Instituto de Ciências Biomédicas, \\ Universidade Federal de Alfenas - Unifal-MG.
}

\section{Resumo}

As ferramentas de comunicação online possibilitam aos estudantes novos meios de aprendizagem, sendo importantes instrumentos nos cursos online. Tendo em vista o foco na aprendizagem colaborativa, uma das ferramentas de destaque é o fórum de discussões e cuja compreensão das interações poderá contribuir na melhoria dos cursos online. Este artigo objetiva analisar, em uma disciplina de Bioquímica, as relações online nos fóruns e verificar indícios de sua utilização, assim como de outras ferramentas de comunicação (chats, wiki etc). Todas estas ferramentas são importantes para o ensino-aprendizagem dos estudantes de um curso, sendo que, evidenciou-se maior uso dos fóruns de discussão que propiciaram maior interação entre os estudantes envolvidos. Ressalta-se que os estudantes demonstraram a necessidade de interação entre si para a própria aprendizagem. A contextualização, a problematização e o incentivo ao diálogo foram indicados como um possível caminho para melhoria do ensino online de Bioquímica.

Palavras-chave: ensino de Bioquímica, ensino online, interação em fóruns

\begin{abstract}
The online communication tools enable students to new ways of learning, and are important tools in online courses. Considering the focus on collaborative learning, one of the tools highlighted is the discussion forum and which interaction understanding of these interactions may contribute to the improvement of online courses. This work aims to analyze the relations in online discussion forums and seek evidence of their use in a biochemistry and to evaluate the use of other learning tools. In addition to the forums, will be presented the evidence of use of other tools (chats, wiki etc). All these are important tools for teaching and learning processes in an online course. It was observed a greater use of discussion forums that promoted a greater interaction between those involved. It is noteworthy that the students highlighted the need for interaction among themselves for their own learning. The contextualization, the questioning and encouraging dialogue were indicated as a possible way to improve Biochemistry online teaching.
\end{abstract}

Keywords: Biochemistry learning, online learning, forums interactions 


\section{Introdução}

A chamada revolução da tecnologia da informação [1], intensificada em meados da década de 1990, vem acrescendo os processos de transformação social, alterando os processos de comunicação e consequentemente interferindo no ensino-aprendizagem.

As novas tecnologias da informação e comunicação (TICs) propiciam às pessoas diversas ferramentas que podem ser utilizadas no contexto educacional, dentre elas os web sites, softwares educacionais, ambientes virtuais de aprendizagens, blogs etc.

O uso das TICs, com destaque para as informatizadas, pode ser parte integrante do processo de ensino-aprendizagem, permitindo a criação de novas estratégias e modos de resolução de problemas ou projetos, nos chamados cursos a distância (EAD) ou também conhecidos como cursos online (quando a colaboração é o foco do curso).

Moore [2] ressalta que a separação entre estudante e professor nos cursos a distância possui um impacto profundo nos processos de comunicação entre os sujeitos. Este impacto, decorrente do distanciamento físico (face a face), pode ser de ordem afetiva, cognitiva, entre outras, e que, de certo modo, influencia diretamente nos processos de ensino-aprendizagem [2], ressaltando os que ocorrem em todos os ambientes virtuais de aprendizagem.

Neste contexto, o EAD tem sido considerado uma alternativa interessante, podendo ser realizado de distintas maneiras, uma vez que este oferece uma maior flexibilidade de horários, exigindo maior gerenciamento do estudo pelo estudante.

O crescente aumento no número de cursos semipresenciais ou a distância, em seus diversos níveis, apresenta-se como um reflexo das mudanças na política, economia e cultura educacional do país, sendo que há uma forte tendência de cursos EAD como meio para "entregar" a informação (broadcasting) para o estudante [3]. Por outro lado, existem cursos com excelentes métodos de trabalho, visando o aprendizado reflexivo, colaborativo para criação de condições significativas e adequadas para a aprendizagem.

Os cursos a distância (EAD), referindo-se aos cursos online (para o contexto deste trabalho), podem se configurar como cursos de qualidade, principalmente quando focados no diálogo e construção colaborativa dos conhecimentos por meio das ferramentas de comunicação online, envolvendo os estudantes, professores, tutores e monitores (entre outros), de modo ativo, interativo e colaborativo.

Esses cursos dependem de ambientes virtuais que se configuram como a sala de 
aula, apresentando diversas ferramentas de disponibilização de materiais e de interação, havendo ambientes com distintas propostas pedagógicas e conjuntos de ferramentas, com o objetivo de auxiliarem no ensino aprendizagem dos estudantes, como por exemplo o Moodle, TelEduc, Tidia, Sakai, eTutor entre outros.

Destacam-se, no contexto do ensino online, as ferramentas wiki, webconferência, chats e fóruns de discussão, sendo o fórum considerado como um dos espaços mais utilizados nos cursos online [4].

Com a ampliação e facilidade de uso dessas ferramentas digitais, associadas às demandas por inovações pedagógicas nos processos de ensino-aprendizagem, torna-se cada vez mais proeminente o número de professores utilizando uma grande diversidade de aplicativos e outras tecnologias, devido principalmente às dificuldades de se representar eventos complexos micro e submicroscópicos, como os Bioquímicos [5, 6], presentes em cursos como de Ciências Biológicas e Química.

Apesar do aumento crescente no uso das TICs, incluindo os ambientes virtuais de aprendizagem (AVAs), ainda existe uma carência de pesquisas que aprofundem a compreensão dos processos de comunicação e aprendizagem nesses ambientes, assim como as que avaliem os materiais utilizados nos processos de ensino.

Além disso, são necessários mais estudos focando a aprendizagem por meio dos ambientes virtuais, incluindo as ferramentas tecnológicas disponíveis nestes ambientes, que possibilitem a compreensão de como os estudantes constroem os conhecimentos online e, deste modo, possibilitar subsídios para reflexão sobre a atuação do professor e tutores, assim como para desenvolvimento de novas ferramentas e métodos.

Neste sentido, buscou-se atender a uma necessidade visivelmente importante de compreender, mesmo que parcialmente, os processos de ensino-aprendizagem relacionados ao ensino online de Bioquímica, de tal modo que se possibilitem formas de melhorar os métodos de trabalho, aumentando o potencial educacional envolvendo o ensino online e o uso das TICs. 


\title{
2. Revisão bibliográfica
}

\subsection{0 ensino online}

A procura por cursos semipresenciais ou a distância/ online vem crescendo, seja pela necessidade de flexibilidade de tempo ou mesmo pela metodologia de ensino inovadora.

Observa-se no ensino online uma nova epistemologia, distinta dos famosos cursos a distância (EAD), como os por correspondência, do Instituto Universal Brasileiro Para compreender melhor essa diferença, apresentam-se dois contextos legais distintos.

Classicamente, apresenta-se o conceito de EAD a partir do artigo $1^{\circ}$ do Decreto $\mathrm{n}^{\circ}$ 2494/ 1998 [7], o qual estabelece esse como:

\begin{abstract}
... uma forma de ensino que possibilita a autoaprendizagem como a mediação de recursos didáticos sistematicamente organizado, apresentados em diferentes suportes de informação, utilizando isoladamente ou combinados e vinculados pelos diversos meios de comunicação. (Art. $1^{\circ}$ )
\end{abstract}

Destaca-se nesta conceituação o aspecto da autoaprendizagem, o que é ainda ressaltado por muitos autores, entretanto, a concepção do ensino online coloca este em discussão, quando se entende que as ferramentas são instrumentos de mediação e que o foco do ensino deve residir na interação e colaboração [8].

No contexto legal, percebe-se a mudança conceitual a partir do artigo $1^{\circ}$ Decreto 5.622/2005 [9], o qual caracteriza a EAD, em seu artigo $1^{\circ}$ como:

... modalidade educacional na qual a mediação didático-pedagógica nos processos de ensino e aprendizagem ocorre com a utilização de meios e tecnologias de informação e comunicação, com estudantes e professores desenvolvendo atividades educativas em lugares ou tempos diversos.

Ressalta-se nesta definição a mudança fundamental de conceituação do EAD, onde se destaca o papel mediacional das TICs, sendo este um processo de ensinoaprendizagem no qual estão envolvidos vários sujeitos, ou seja, tira-se o peso excessivo do individual e começa-se a olhar para o relacional.

De toda forma, a definição do decreto [9] acaba por não explicitar a ação ativa, interativa e colaborativa dos envolvidos, mas deixa indícios para tal, sendo este decreto o resultado das transformações socioculturais e da visão que se tinha sobre EAD.

A colaboração e comunicação entre participantes de um curso online podem ser mediadas por instrumentos de comunicação síncrona (instantânea, como um bate-papo) ou assíncrona (ao longo do tempo, como um fórum), destacando-se o uso do fórum. 
O fórum de discussões propicia um contato mais profundo entre os participantes do curso, sendo um local em que os discentes se ajudam, atuando como parceiros entre si ou com o professor, tutor e monitor, com o objetivo de construir conhecimento sobre determinado assunto [10], sendo considerado como ferramenta fundamental para a interação e aprendizagem dos estudantes.

Ressaltam-se algumas das vantagens desta ferramenta, baseado em Maria Teresa Meirelles Leite [11]:

1. propicia tempo para pesquisa prévia e reflexão anterior à postagem;

2. favorece as funções cognitivas, tais como: solucionar, observar, organizar, opinar etc;

3. favorece a organização das ideias, a partir da expressão no formato escrito;

4. pode proporcionar o aprofundamento em determinadas ideias e conceitos;

5. proporciona uma maior mediação por parte do professor e tutores;

6. propicia meio para interação de todos.

Destaca-se, para os fóruns, a possibilidade de múltiplas interações, seja pela multiplicidade de diálogo entre todos envolvidos, ou seja, pela viabilidade de se integrar nos fóruns múltiplas ferramentas de diálogo (imagens, vídeos etc.). Essa multiplicidade potencializa a construção de conhecimentos, integrando diversas linguagens e caminhos de diálogo, que resultam em fluxos semânticos diferenciados.

Os fóruns online são caracterizados por uma relação dialógica acompanhada pelos vários discursos realizados pelos participantes [12]. Este dialogismo, baseando-se em Bakhtin [13], é referente à ideia de que as mensagens postadas pelos interlocutores respondem aos enunciados anteriores, de tal forma que a autoria original é minimizada uma vez que faz parte de uma cadeia de enunciados na qual aqueles coparticipam.

Deste modo, à medida que um participante do fórum posta uma mensagem, esta fará parte do coletivo de mensagens, tornando explícita a contribuição discursiva deste a qual será parte subsequente de novas mensagens.

O espaço de comunicação do fórum online multiplica e complexifica o texto, uma vez que cada interlocutor ao colocar sua contribuição discursiva poderá ser lido e discutido por todos, tornando-se assim abertos à retórica de qualquer participante do fórum. É facultado aos participantes do fórum acesso irrestrito, em qualquer momento, às mensagens anteriores e às reflexões que permitem novas entradas discursivas [12]. 


\subsection{Ensino de Bioquímica a distância}

O ensino da disciplina de Bioquímica no presencial é complexo e mais ainda quando trabalhado a distância, pois são muitos conceitos envolvidos e principalmente os conceitos relacionados à Química, que são considerados abstratos e difíceis quando perguntado a estudantes do ensino a distância.

Além disso, percebe-se que há pouca motivação em desenvolver novos métodos para ensino-aprendizagem de Bioquímica, que poderiam tornar as aulas mais atraentes e interessantes [14], predominando ainda as aulas expositivas e as práticas demonstrativas.

A ausência presencial e constante do professor nos cursos a distância complexifica ainda mais o processo de ensino-aprendizagem, fazendo-se necessário um maior comprometimento por parte dos estudantes, assim como do professor, tutores (presenciais e a distância) e monitores, que apresentam grande importância no processo de ensino-aprendizagem de todos os estudantes, pois estes possuem a função de fazer com que os estudantes se interajam com uma maior frequência e busquem juntos construir um maior conhecimento por meio das participações nos fóruns, construções coletivas de textos no wiki, além das participações em chats e webconferências.

Muitos estudos foram e estão sendo realizados para ajudarem os estudantes a distância a poderem apresentar menos dificuldades neste tipo de disciplina e várias pesquisas apontam que a interação e colaboração são de extrema importância, afinal, a questão central é a construção de conhecimentos a partir da interação dos sujeitos [12].

Além disso, o uso de mídias educacionais pode auxiliar fortemente no ensino online, como por exemplo, na manipulação de moléculas ou a simulação de atividades que poderiam ser feitas em laboratórios e em aulas presenciais.

Estas não são as únicas opções para ensinar Bioquímica a estudantes de cursos online, os professores também podem fazer usos de videoaulas, wikis, webconferência, que são consideradas como ferramentas de grande importância para o aprendizado dos estudantes, além de algumas aulas presenciais que são realizadas nas próprias faculdades ou nos polos de apoio. 


\section{Objetivos}

Buscou-se compreender os processos de ensino-aprendizagem dos conceitos de Bioquímica, em uma disciplina de Bioquímica de um curso online, focando o olhar para as comunicações nos fóruns de discussão, tendo este como um estudo exploratório.

Destacaram-se os seguintes objetivos específicos:

1. obter indícios dos processos de ensino-aprendizagem dos conceitos de Bioquímica, a partir da análise parcial dos diálogos do fórum sobre a introdução ao metabolismo.

2. obter indícios sobre o processo do trabalho colaborativo entre estudantes/ professores/ tutores durante as atividades da disciplina.

\section{Procedimentos}

O projeto apresentou uma abordagem mista (quantitativa e qualitativa), com diversidade na forma de coleta dos dados e avaliação dos mesmos e desenvolveu-se a partir dos dados de uma disciplina de Bioquímica, do curso de Licenciatura em Ciências Biológicas (modalidade EAD) de uma Universidade Federal.

Para alcançar os objetivos apresentados, construiu-se uma visão geral do uso das ferramentas, com foco específico no fórum, a partir de uma das temáticas desenvolvidas ao longo da disciplina, para aprofundamento da compreensão dos processos de construção dos conhecimentos.

A análise geral ocorreu a partir da correlação dos dados de acesso e utilização das ferramentas pelos usuários (dados de relatórios do Moodle), com os dados de uso dos fóruns (os usuários autorizaram o uso dos dados, eletronicamente - pelo Moodle) e dados dos questionários pré e pós-disciplina.

Para avaliação dos fóruns, utilizou-se um método de organização de fóruns online descrita por Hornink [8], a qual possibilita a organização das informações e a criação de fluxos semânticos que possibilitaram indícios dos caminhos no ambiente para a construção dos conhecimentos. Dentro do método de Hornink [8], há a criação de grafos ${ }^{1}$ de interações dos fóruns e, para isto, utilizou-se o aplicativo inMapMoodle [13].

Este aplicativo permite, dentro do Moodle, a criação de grafos de interação (mapas de interação), com os sentidos das interações (fluxo da mensagem), indicação do tipo de

1 Estrutura imagética no qual vértices são ligados por arestas, sendo que estas podem não indicar direção. No caso do grafo com direção, pode-se denominar este como grafo direcionado, grafo orientado ou digrafo. 
participante (estudante, tutor e professor) e quantidade de mensagens (escala de cores).

Para avaliar o fórum escolhido, enumeraram-se os tópicos e as suas mensagens e, posteriormente, classificou-se estas de acordo o tipo de interação [8] (Anexo A).

Após organização dos dados, buscou-se conectar as mensagens pela temática que as mesmas abordavam, evidenciando os fluxos discursivos entre os enunciados.

Aplicaram-se questionários pré e pós-disciplina, além de observado os registros de acesso ao ambiente, ferramentas e histórico da discussão no fórum.

\subsection{Descrição e caracterização da amostra}

Realizou-se a pesquisa durante uma disciplina de Bioquímica II de um curso online de uma Universidade Federal, na qual se utilizou como ambiente de aprendizagem o Moodle. A disciplina possui 60 horas e é desenvolvida em 6 semanas de atividades concentradas.

Fez parte da amostra de estudos: estudantes de graduação (20 no início), tutores do curso (4), monitor da disciplina (1), e professor (1), totalizando cerca de 26 envolvidos.

Fez-se a análise das interações a partir de um recorte da disciplina, optando-se pelo fórum 1 (Tópico 1 - Introdução ao metabolismo), no qual se abordou a introdução ao metabolismo, a partir dos conceitos básicos da termodinâmica e via glicolítica, por meio de um estudo dirigido dinâmico.

Os estudantes deveriam postar suas ideias para resoluções das questões, dúvidas sobre estas, respostas aos colegas e com isso construírem, coletivamente, as respostas para todo o estudo. Destaca-se que, para cada fórum, um grupo fora responsável pela moderação, motivo pelo qual se nomeou o estudo dirigido de dinâmico.

Cada estudante deveria ter, pelo menos, três participações significativas (relacionadas com a temática) e, destas três participações, uma deveria ser resposta a um colega, dessa forma, buscava-se induzir a interação entre os participantes.

O fórum 1 apresentou 12 tópicos, com um total de 69 mensagens, sendo essas postadas pelos estudantes, professor, tutora e monitora, sendo que participaram 12 pessoas deste fórum (um professor, uma tutora, uma monitora e nove estudantes), durante um período de 9 dias de discussões. 


\subsection{Coleta de dados}

Houve coleta de dados automática pelo ambiente Moodle (registro de acesos e participações no fórum) e por meio de questionários pré e pós-disciplina.

As ações dos usuários na disciplina são registradas pelo próprio sistema do ambiente Moodle, incluindo acesso à disciplina e ferramentas de trabalhos, assim como as mensagens postadas nos fóruns e chats.

Os questionários pré e pós-disciplina tiveram como objetivos avaliar o conhecimento das ferramentas do Moodle e as dificuldades nos tópicos, assim como as estratégias utilizadas ao longo do curso, sendo que se construíram questões fechadas, usando-se predominantemente escalas de atitudes, baseadas em Likert [15].

Segue abaixo os eixos de questionamentos dos questionários:

Pré-disciplina: Conhecimentos sobre as ferramentas do Moodle; valoração da importância das ferramentas do Moodle para o aprendizado; valoração das estratégias de ensino para a aprendizagem; modo de utilização prévio da ferramenta fórum.

Pós-disciplina: avaliação dos conhecimentos nos tópicos da disciplina; valoração do uso das ferramentas para a aprendizagem; valoração das estratégias de ensino para a aprendizagem usadas na disciplina; dificuldades no uso do Moodle. No primeiro questionário, as questões buscavam conhecer qual era a função de cada envolvido na disciplina, se os estudantes apresentavam alguma dificuldade no ambiente virtual, qual das ferramentas eles acreditavam apresentar maior importância para seu ensinoaprendizagem, se apresentavam algum conhecimento prévio sobre o conteúdo da matéria da disciplina.

Após o final da disciplina, aplicou-se o segundo questionário com o principal objetivo de compreender quais foram as ferramentas que os estudantes consideraram importantes para sua aprendizagem e qual a importância de cada envolvido da disciplina.

\subsection{Análise do fórum}

A complexidade da organização do fórum de discussão online exige uma análise mais detalhada que tenha em vista as distintas interações, observando as entradas de mensagens de forma cronológica, integrando os tópicos e participantes, buscando criar um panorama do fórum que não se limite à descrição de cada um dos tópicos, observando também a historicidade envolvendo os participantes. 
Para tanto, analisou-se o fórum buscando a observação sob uma perspectiva multidimensional, numa analogia entre distintos bancos de dados se interagindo. Nesse contexto, sistematizou-se o fórum segundo Hornink [8], possibilitando a visualização e compreensão da dinâmica geral do fórum.

A organização do fórum possibilitou a criação de um mapa visual das interações dos fóruns, levando em consideração a análise semântica dos enunciados e os fluxos de interações sociais, o que possibilita a construção de indícios de como os usuários utilizaram a(as) ferramenta(as) para se comunicarem e construírem conhecimentos.

\section{Resultados e discussões}

Os resultados do questionário de pré-avaliação indicaram que a maioria dos estudantes apresentavam algum conhecimento sobre os conteúdos de Bioquímica, provavelmente devido algumas sobreposições de disciplinas anteriores, assim como pelos conhecimentos básicos do ensino médio.

Além dos conhecimentos prévios sobre os conteúdos específicos, torna-se imperativo avaliar as dificuldades com o uso da plataforma e a importância dada às ferramentas, uma vez que esses fatores influenciam diretamente no processo de ensinoaprendizagem.

Fez-se a avaliação das dificuldades de uso do Moodle, utilizando uma escala de 1 a 5 (de menor para maior dificuldade), antes e após a disciplina (Tabela 1), observando-se que $20 \%$ dos estudantes possuíam mais dificuldades (escala 3 e 4 ) e que, após a disciplina, essa dificuldade no uso do Moodle diminuiu ( $90 \%$ com pouca dificuldade).

Tabela 1. Avaliação da percepção da dificuldade do uso do Moodle pelos estudantes, utilizando escala de 1 a 5 (da menor para maior dificuldade).

\begin{tabular}{lcc}
\hline Escala & Antes & Depois \\
\hline 1 -Pouca & $60 \%$ & $90 \%$ \\
2 & $20 \%$ & $10 \%$ \\
3 & $10 \%$ & $0 \%$ \\
4 & $10 \%$ & $0 \%$ \\
5 -Muita & $0 \%$ & $0 \%$ \\
\hline
\end{tabular}

Essa mudança pode ter ocorrido, em parte, pelo fato da disciplina cursada investir no uso de diversas ferramentas do Moodle, destacando que esse uso ocorre, 
prioritariamente, de modo colaborativo e com objetivos específicos.

Além das dificuldades, avaliou-se a percepção, pelos estudantes, da importância das ferramentas disponíveis no ambiente, como: chat, webconferências, fóruns de discussão, wiki, videoaulas (Tabela 2).

Observa-se na Tabela 2 que a maioria dos estudantes informou que todas essas ferramentas eram muito importantes ou importantes para a aprendizagem (não houve respostas para pouco importante ou sem importância), destacando-se, antes da disciplina, as atividades práticas presenciais, resolução de problemas e tira dúvida no bate-papo.

Destaca-se que, após a disciplina, houve algumas mudanças nessa percepção, com grande redução da consideração pessoal da importância das aulas práticas e ferramenta de bate-papo no Moodle, assim como aumento da importância do estudo dirigido.

Tabela 2. Valoração da percepção da importância das estratégias de ensino-aprendizagem, pelos estudantes, antes e depois da disciplina ocorrer.

\begin{tabular}{lcccc}
\hline & \multicolumn{2}{c}{ Muito importante } & \multicolumn{2}{c}{ Importante } \\
Parâmetro & Antes & Depois & Antes & Depois \\
\hline Discussões em Fórum - Moodle & $62,5 \%$ & $70 \%$ & $37,5 \%$ & $30 \%$ \\
Estudo Dirigido no wiki - Moodle & $75 \%$ & $90 \%$ & $25 \%$ & $10 \%$ \\
Tirar dúvida no bate-papo - Moodle & $87,5 \%$ & $40 \%$ & $12,5 \%$ & $40 \%$ \\
Resolução de problemas - Moodle & $100 \%$ & $70 \%$ & $0 \%$ & $30 \%$ \\
Uso de animações e simulações - Moodle & $75 \%$ & $70 \%$ & $25 \%$ & $30 \%$ \\
Vídeo-aulas resumo - Moodle & $75 \%$ & $80 \%$ & $25 \%$ & $20 \%$ \\
Atividades práticas - presenciais & $100 \%$ & $30 \%$ & $0 \%$ & $60 \%$ \\
\hline
\end{tabular}

Obs.: Destacou-se muito importante e importante, uma vez que apresentam praticamente a totalidade das indicações.

Cerca 95\% teve sua primeira experiência no uso do wiki como ferramenta didática, sendo que, na proposta da disciplina, os estudantes discutiam as questões no fórum e consolidavam a resposta no wiki.

Apesar de ser a primeira experiência para muitos dos estudantes, percebeu-se nas construções no wiki um avanço, ao longo da disciplina, no modo de trabalho. Inicialmente, o wiki se compôs de trechos de textos inseridos por estudante e, ao fim, com a interação e intervenção nos textos um dos outros, entretanto, ainda distante de um texto de fato colaborativo.

Além do uso das ferramentas, avaliou-se a percepção da importância dos 
Pesquisa em Ensino: O ensino-aprendizagem online de Bioquímica e as ferramentas de mediação

envolvidos (Tabela 3), destacando-se, além do papel do professor, os próprios estudantes.

O resultando é condizente com as estratégias utilizadas durante a disciplina, uma vez que essas estimularam a colaboração entre estudantes, assim como a moderação de atividades pelos próprios estudantes, indicando um papel diferenciado dos mesmos no processo de ensino-aprendizagem.

Tabela 3. Percepção dos estudantes sobre a importância dos envolvidos no processo de ensinoaprendizagem.

\begin{tabular}{lcccc}
\hline Envolvidos & Muito importante & Importante & Pouco importante & Sem importância \\
\hline Professor & $100 \%$ & $0 \%$ & $0 \%$ & $0 \%$ \\
Tutor a distância & $50 \%$ & $40 \%$ & $10 \%$ & $0 \%$ \\
Tutor presencial & $50 \%$ & $30 \%$ & $20 \%$ & $0 \%$ \\
Monitor & $60 \%$ & $30 \%$ & $0 \%$ & $10 \%$ \\
Estudantes & $90 \%$ & $10 \%$ & $0 \%$ & $0 \%$
\end{tabular}

Para a avaliação e obtenção de indícios do modo de atuação dos mesmos, optou-se por um recorte da disciplina, focando-se no primeiro tópico da mesma (Introdução ao metabolismo e glicólise).

Nesse primeiro tópico houve um estudo dirigido, contando com 3 videoaulas de apoio, sendo que os acessos, por perfil, estão apresentados na Tabela 4.

Tabela 4. Número de acessos dos participantes (12) da disciplina de Bioquímica às atividades do tópico.

\begin{tabular}{|c|c|c|c|c|}
\hline Perfil & Fórum $1^{1}$ & Videoaula $1^{2}$ & Videoaula $2^{3}$ & Videoaula $3^{4}$ \\
\hline Estudantes & 1069 & 81 & 22 & 18 \\
\hline Tutores & 295 & 13 & 3 & 2 \\
\hline Monitora & 262 & 3 & 1 & 1 \\
\hline Professor & 119 & * & * & * \\
\hline Total & 1745 & 97 & 25 & 20 \\
\hline
\end{tabular}

* Uma vez que a videoaula foi gravada e postada pelo professor, não se avaliou o acesso pelo mesmo.

${ }^{1}$ Discussões sobre conceitos introdutórios ao metabolismo.

${ }^{2}$ Introdução ao metabolismo.

${ }^{3}$ Conceitos básicos de termodinâmica.

${ }^{4}$ Glicólise.

Percebe-se que houve uma redução nos acessos às videoaulas, entretanto, essa diminuição não indica necessariamente uma redução de visualizações, uma vez que, no início os alunos utilizaram mais o acesso à videoaula pelo Moodle, depois passaram a ter um maior acesso diretamente pelo canal do Youtube.

Para compreender a dinâmica discursiva do fórum 1, avaliou-se o mesmo segundo método descrito por Hornink [8], gerando-se, primeiramente, o grafo de interações, por 
meio do aplicativo inMapMoodle [14], para se obter uma visão geral das interações (Figura 1). Neste método, cada aluno é um vértice de um grafo orientado, sendo que o número de mensagens é representado por uma escala de cores (ver legenda) e o sentido da mensagem no fórum por setas. Além disso, a espessura da do contorno da elipse indica o papel do usuário no curso.
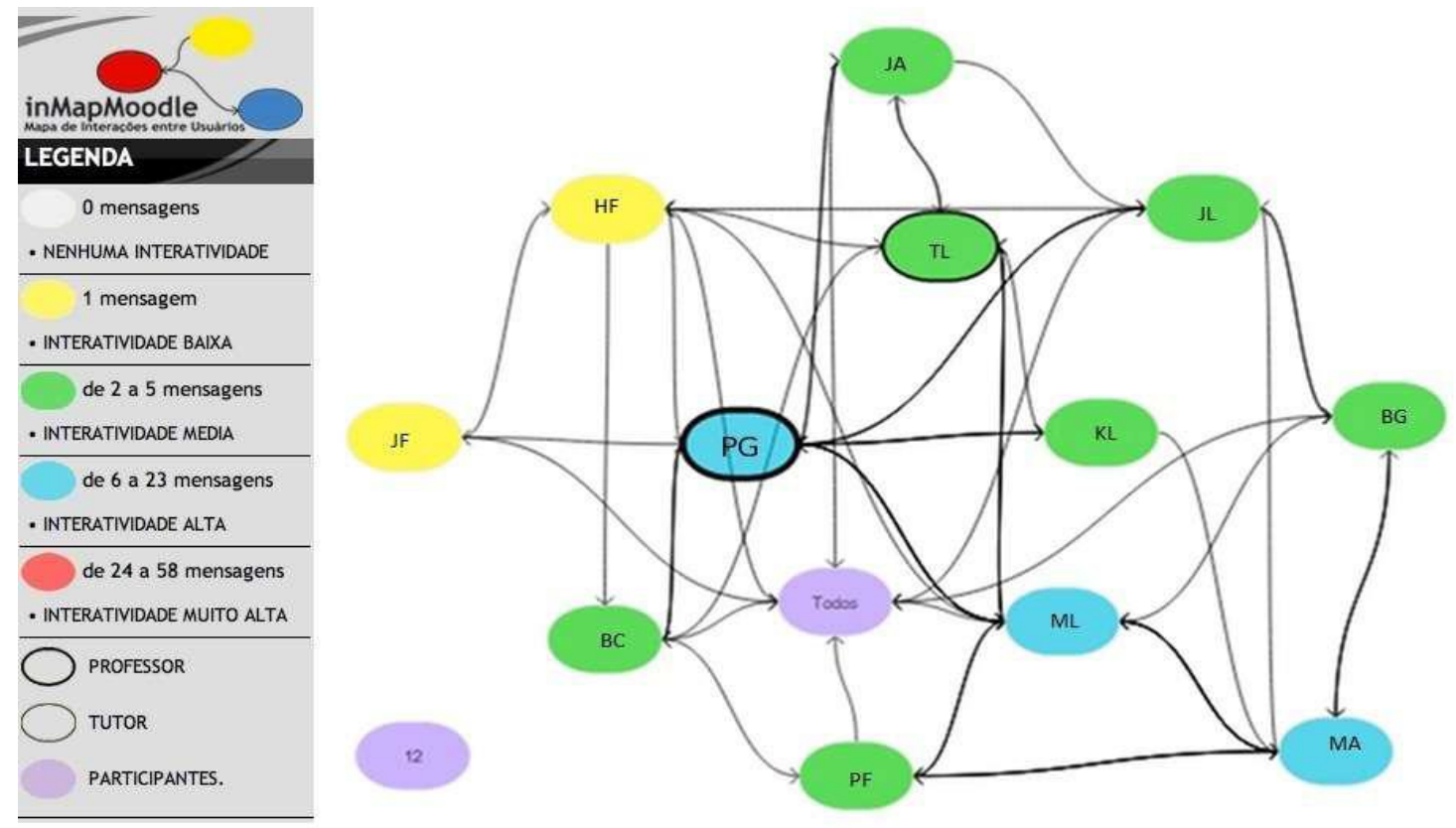

Figura 1. Grafo de interações do fórum de discussões do tópico 1, indicando fluxos dos diálogos e quantificação de mensagens.

Pode-se destacar a distribuição do número de participações na figura 1 (a maior parte está verde, seguida de azul), indicando a participação significativa da maior parte dos envolvidos, assim como o número de conexões entre os usuários, com indicação de flechas de duplo sentido (indício de diálogo).

Seguindo o método de avaliação do fórum, classificou-se as mensagens pelo tipo de interação [8] e sistematizou-se as mesmas em uma planilha (Figura 2), com ambos eixos em ordem cronológica, com indicação dos períodos de discussões (preenchimento cinza na das células) e de flechas para conectar mensagens dentro da mesma temática (nesse caso, conceitos da termodinâmica), para visualização dos fluxos semânticos entre as diferentes mensagens.

Cada mensagem pode ser representada por, pelo menos, uma classe, que é composta por uma sigla com quatro componentes (Anexo A), os quais indicam, respectivamente: 1. ação; 2. relação com o fluxo do discurso no fórum; 3. classificação da 
Pesquisa em Ensino: O ensino-aprendizagem online de Bioquímica e as ferramentas de mediação

mensagem com relação ao fluxo do discuso; 4. classificação do enunciado

Figura 2. Organização dos tópicos da discussão em ordem cronológica (vertical e horizontal) e indicação dos fluxos semânticos (setas).

\begin{tabular}{|c|c|c|c|c|c|c|c|c|c|}
\hline Data & $21 / 10 / 2011$ & $22 / 10 / 2011$ & $23 / 10 / 2011$ & \begin{tabular}{|l}
$24 / 10 / 2011$ \\
\end{tabular} & $25 / 10 / 2011$ & $26 / 10 / 2011$ & $27 / 10 / 2011$ & \begin{tabular}{|l}
$28 / 10 / 2011$ \\
\end{tabular} & 29/10/2011 \\
\hline $\begin{array}{l}\text { Tópico 1: Bioenergética } \\
\text { eas Reaçöes Química }\end{array}$ & 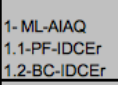 & 1.3-MLLIDRE & $\begin{array}{l}\text { 1.1.1-MA-IDCRe } \\
\text { 1.1.2-MLLIDRE }\end{array}$ & & & & & & \\
\hline $\begin{array}{l}\text { Tópico 2: Questãa } 1 / 1{ }^{\circ} \\
\text { Lei da Termodinâmica }\end{array}$ & PF-AIAE & & & & & & & & \\
\hline $\begin{array}{l}\text { Tópico 3: Questão } 2 \\
\text { Leis da Termodinâmica }\end{array}$ & $\begin{array}{l}\text { 3-PFF-AIAP } \\
\text { 3.1-ML-IDCRe }\end{array}$ & & & $\begin{array}{l}\text { 3.2-MA-IDCO3. } \\
\text { 2.1-ML-LDCRe } \\
\text { 3.2.2.MA-IDCM }\end{array}$ & $\begin{array}{l}\text { 3.2.3.PF-IDCRe } 32.4 \\
\text { WA-IDCM }\end{array}$ & & & & \\
\hline Tópico 4: Questão 3 & & 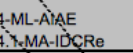 & & & & 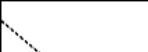 & & & \\
\hline Tópico 5: Metabolismo & & & & $\begin{array}{l}\text { 5.1.HF-IDCRe } \\
\text { 5.2. }\end{array}$ & & 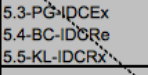 & & $\begin{array}{l}\text { 5.6-PG-IDCQ } \\
\text { 5.7.PG-IDCQ }\end{array}$ & \\
\hline $\begin{array}{l}\text { Tópico 6: Energia de } \\
\text { Ativaçăo }\end{array}$ & & & & 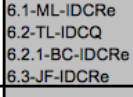 & & 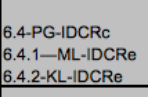 & & & \\
\hline Tópico 7: Glicólise & & & & 7.JFAA & & & & & \\
\hline $\begin{array}{l}\text { Tópico 8: Leis da } \\
\text { Termodinâmica }\end{array}$ & & & & 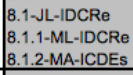 & & & & & \\
\hline $\begin{array}{l}\text { Tópico 9:Oxidaçăo dos } \\
\text { Nutrientes }\end{array}$ & & & & |a-VLAAAQ & & & & 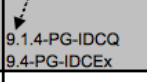 & - IDCRe \\
\hline $\begin{array}{l}\text { Tópico 10: Metabolismo } \\
\text { e Exercicio }\end{array}$ & & & & 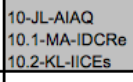 & $\begin{array}{l}\text { 10.2.1-TL-IDCRe } \\
0.21-1 \text {-ILIOCEX }\end{array}$ & & & & \\
\hline $\begin{array}{l}\text { Tópico 11: Controle por } \\
\text { Compartimentalizaçăo }\end{array}$ & & & & & 11-JA-AAAE & & & 11.2.PG-IDCRX & \\
\hline Tópico 12: Glicólise & & & & & & & & $\int_{12.2 .1-P G-1 D C Q}^{*}$ & \\
\hline
\end{tabular}

Obs. As siglas representando as classes constam no Anexo A.

Analisando-se a Figura 2, constata-se que a discussão do fórum, ocorrida em 9 dias, possui um número significativo de tópicos e de conexões entre estes, com participação de diversos envolvidos. Ressalta-se o número de tópicos que ocorreram simultâneos, o que possibilitou as conexões indiretas entre os fluxos discursivos para a construção dos conhecimentos envolvendo a termodinâmica e a bioenergética.

Além disso, pelo tipo de mensagem, observa-se sequência de diálogos iniciadas com problemas ou questionamentos, seguidas de esclarecimentos, reflexões, explicações e reconduções, sendo que praticamente não houve mensagens de ruptura de diálogo.

Quantificou-se o número de mensagens, por classe de interação, por perfil de envolvido (Tabela 5), observando-se claramente a distinção dos modos de participação. 
Pesquisa em Ensino: O ensino-aprendizagem online de Bioquímica e as ferramentas de mediação

Tabela 5. Quantificação das classes (tipo de interação discursiva) das mensagens postadas no fórum 1.

\begin{tabular}{lcccc}
\hline Classificação da mensagem & Professor & Monitor & Tutor & Estudantes \\
\hline AIAQ - Questionamento & - & - & - & 5 \\
AIAE - Exposição simples & - & - & - & 3 \\
AIAP - Apresenta problema & - & - & - & 3 \\
IDCEx - Explicação & 2 & - & - & 2 \\
IDCQ - Questionamento & 6 & 1 & 2 & - \\
IDCRc - recondução & 2 & - & - & - \\
IDCRx - discussão & 2 & - & - & 1 \\
IDCEs solicita esclarecimentos & - & 1 & - & 2 \\
IDCRe - exposição simples & - & 7 & 2 & 21 \\
IDCM - Motivacional & - & 2 & - & 2 \\
IDRE - Encerramento & - & - & - & 1 \\
IICQ - Questionamento & - & - & - & 1 \\
IICEs - Esclarecimento & - & - & - & 1 \\
Total & 12 & 11 & 4 & 42
\end{tabular}

Obs. As siglas representando as classes constam no Anexo A.

O perfil de interação se correlaciona com os papéis desenvolvidos, assim como com os aspectos culturais dos envolvidos e as relações institucionais entre esses.

As mensagens do professor predominaram na classe IDCQ (interativa direta de continuidade por questionamento), destacando seu papel de moderar a discussão, buscando o aprofundamento da temática a partir do questionamento ao aluno, assim como pela discussão da temática e recondução de temas importantes.

O monitor teve suas intervenções principalmente como respostas (exposição simples), ou seja, respondendo a dúvida/ questionamento de um colega e, de similar, o tutor teve pouca interação neste fórum, dividindo-se entre exposições simples e questionamentos.

De fato, o papel do professor em cursos online e presenciais é de instigar as discussões e reconhecer (para melhor atuar) até onde o aluno consegue discutir e construir novos conhecimentos com o auxílio dos demais colegas, monitores e professores. Para tanto, o professor demanda um maior conhecimento dos conceitos abordados, assim como dos aspectos didáticos envolvidos no ensino-aprendizagem. $O$ tutor e o monitor tem um papel diferenciado de ajudar os estudantes, inclusive apresentando algumas informações que possam ser importantes para seu 
desenvolvimento e resolução do problema.

Apresenta-se um pequeno excerto do fórum 1 para ilustrar uma sequência discursiva entre duas estudantes (PF, ML) e a monitora (MA):

3-PF-AIAP (Inicial): A segunda lei refere-se a transferência de energia, porque algumas reações ocorrem espontaneamente e outras necessitam de energia. Alguém pode me ajudar a compreendê-la melhor?

entropia- (S) energia que não realiza trabalho

entalpia- $(\mathrm{H})$ é a energia total de um sistema

energia livre $(G)$ é a energia capaz de realizar trabalho, sob temperatura e pressão constante.

A $2^{\circ}$ lei é dada pela fórmula $\mathrm{G}=\mathrm{H}-\mathrm{TS}$, sei que se for negativo a reação é espontânea e se for positivo a reação não é espontânea, MAS NÃO CONSIGO ASSOCIAR ISSO A PRÁTICA DAS REAÇÕES, COMO FAÇO?

3.1-ML-IDCRe (Continuidade, Expositiva): PF não entendi muito bem sua pergunta, mas vou postar o que entendi dessa lei: nela vai ocorrer transferencia de energia, envolvendo entalpia, entropia, e energia livre, portanto qdo temos energia livre negativo, a reação será espontânea, liberando muita energia e a entropia tbm será maior (reagente maior que produto), logo maior entropia=positivo e menor entropia=negativo, pois o universo está sempre em desordem.

3.1.2-MA-IDCRe (Continuidade, Expositiva): Oi PF e ML vou tentar ajudar vocês!

A $2^{\circ}$ lei da termodinâmica é aquela que diz que você não pode ganhar nem perder energia, mais sim que há a transferência de energia, ela postula que os processos favoráveis ocorrem espontaneamente e que os sistemas sempre caminham para o estado de energia mais baixo.

Depois dá uma olhadinha no InfOnline, no texto de bioenergética que acho que vai ajudar vocês!

3.2-MA-IDCQ (Continuidade, Questionamento): PF como você disse mais acima algumas reações acontecem espontaneamente e outras já não ocorrem espontaneamente, mais apesar disso elas podem coexistir com as espontâneas, vocês sabem me dizer como essa coexistência pode acontecer?

3.2.1-ML-IDCRe (Continuidade, Expositiva): MA, vou tentar te responder: seria por acoplamento de energia, onde uma reação espontânea se junta com a não espontânea, esta por sua vez se acopla com a espontânea para usar a energia, estou certa????

3.2.2-MA-IDCM (Continuidade, Motivacional): É isso mesmo ML, quando uma reação não espontânea coexiste com reações espontâneas e essa coexistência é denominada como acoplamento energético

3.2.3-PF-IDCRe (Continuidade, Expositiva): Complementando o que foi dito pela ML, no acoplamento energético uma reação favorável (exergônica) transfere energia para uma reação menos favorável (endergônica) possibilitando assim que esta reação aconteça, que pode ser feito pela associação de compostos fosforilados, que quando clivados liberam energia para que a reação menos favorável possa acontecer

3.2.4-MA-IDCM (Continuidade, Motivacional): É isso mesmo PF e ML, se restar mais alguma dúvida postem aqui que tentarei ajuda-las!

Observa-se que após a primeira mensagem (Ativa, Inicial, Aditiva de problematização, todas demais são mensagens interativas de continuidade, ou seja, de algum modo estimulam a continuidade do diálogo, sendo que, ao longo do diálogo, há 
uma mensagem de questionamento do monitor, que busca aprofundar/ esclarecer a temática abordada.

O monitor também insere duas mensagens motivacionais que são importantes para manter o diálogo aberto, incentivando os estudantes a manterem a discussão no tópico ou novo tópico.

\section{Conclusões}

A procura por cursos a distância é crescente, fazendo-se importante compreender o modo que o processo de ensino-aprendizagem vem ocorrendo, para se pensar em melhores formas de atuação e uso das TICs.

Dentre as questões trabalhadas, evidenciou-se nesta disciplina que a interação e a colaboração foram consideradas como fundamentais nos processos de ensinoaprendizagem online, uma vez que as avaliações dos alunos sobre o uso do fórum e wiki, assim como, com menor ênfase, o uso dos chats e webconferências indicaram a importância destes.

As avaliações dos estudantes indicaram que o fórum foi a principal ferramenta no ambiente Moodle, uma vez que por meio deste que houve uma maior interação entre os estudantes e os demais envolvidos na disciplina e foram neles que puderam postar suas dúvidas, ajudar os colegas, ou seja, interagirem.

Aqueles que tiveram maior número de interações foram os que se declararam com menos dúvidas sobre os conteúdos ao fim da disciplina, reiterando a importância da interação e colaboração, destacando seu papel em sua própria aprendizagem.

Sobre o uso das ferramentas colaborativas no ensino de Bioquímica, evidenciou-se para esta disciplina que o método de discussão de problemas contextualizados, em grupos moderados nos fóruns (pelos próprios alunos com interação do professor, tutor e monitor), seguido pela escrita coletiva no wiki, foi a principal estratégia e a mais aceita e importante para aprendizagem pelos estudantes .

\section{Referências}

[1] Castells MA. Sociedade em Rede: A era da informação: economia, sociedade e cultura. v.1. 2ª ed. São Paulo: Paz e Terra, 1999.

[2] Moore MG. (Ed.). Contemporary issues in american distance education. New York: Pergamon Press; 1990. 
[3] Prado MEBB, Valente J A. A educação a distância possibilitando a formação do professor In: MORAES MC. (org). Educação a distância: fundamentos e práticas.

Campinas: Núcleo de Informática Aplicada à Educação/UNICAMP.

[4] Constantino GD. Discurso didáctico electrónico: los modos de interacción discursiva en el aula virtual en contraste con el aula presencial. Rev. Linguagem em (Dis)curso. 2006; 6(2). Disponível em: <http://www3.unisul.br/paginas/ensino/pos/linguagem/0602/05.htm>. Acesso em: 06 de ago. 2007.

[5] Whitehead JP, Pence HE. Using Computers to teach Biochemistry. Biochemistry and Molecular Biology Education 2002; 30(3): 206-207.

[6] Buckley BC. Interactive Multimedia and model-based learning in biology. International Journal of Science Education 2000; 22(9): 895-935.

[7] Brasil. Decreto no 2.494, de 10 de fevereiro de 1998. Regulamenta o art. 80 da Lei 9.394, de 20 de dezembro de 1996, e dá outras providências.

[8] Hornink GG. Cartografando online: caminhos da informática na escola com professores que elaboram conhecimentos em formação contínua. Campinas. 306f.. Tese (doutorado em ciências) - Instituto de Geociências, Universidade Estadual de Campinas, 2010.

[9] Brasil. Decreto no 5.622, de 19 de dezembro e 2005. Regulamenta o art. 80 da Lei 9.394, de 20 de dezembro de 1996, que estabelece as diretrizes e bases da educação nacional.

[10] Campos FCA, Santoro FM, Borges MRS, Santos N. Cooperação e aprendizagem online. Rio de Janeiro: DP\&A, 2003.

[11] Leite TM. O ambiente virtual de aprendizagem Moodle na prática docente: conteúdos pedagógicos. Versão Digital, 2006. Disponível em:

http://www.virtual.unifesp.br/cursos/oficinamoodle/textomoodlevvirtual.pdf. Acesso: 08 de jun. 2013.

[12] Zacharias VLCF. Vygotsky e a educação, 2007. Disponível em:

<http://www.centrorefeducacional.com.br/vygotsky.html>. Acesso em: 12 de abr. 2009.

[13] Ferraz PFO, Campos RS, Silva EJ, Silva RB, Balbino RR, Souza MM, Hornink GG. InMapMoodle, 2012. Patente: Programa de Computador. Número do registro:

014120000886. Título: "inMapMoodle", Instituição de registro: INPI - Instituto Nacional de Propriedade Industrial.

[14] Yokaichiya DK. O ensino a distância aplicado a uma disciplina de Bioquímica Bioquímica da nutrição. Dissertação de Mestrado [Bioquímica], Universidade Estadual de Campinas. 2001.

[15] Likert RA. A technique for the measure of attitudes. Archives of Psychology 1932; 140 : $5-55$. 
Anexo A. Classificação de mensagens em fluxos discursivos.

\begin{tabular}{|c|c|c|c|c|c|}
\hline Ação & $\begin{array}{c}\text { Relação com o fluxo } \\
\text { do discurso no } \\
\text { fórum }\end{array}$ & $\begin{array}{l}\text { Classificação da mensagem } \\
\text { com relação ao fluxo do } \\
\text { discurso }\end{array}$ & $\begin{array}{l}\text { Classificação do } \\
\text { enunciado }\end{array}$ & Sigla & Resumo descritivo \\
\hline \multirow{3}{*}{$\begin{array}{l}\text { Ativa } \\
\text { (inicia } \\
\text { nova } \\
\text { discussão } \\
\text { ) }\end{array}$} & \multirow{3}{*}{$\begin{array}{l}\text { Inicial } \\
\text { (Inicia um fluxo } \\
\text { discursivo) }\end{array}$} & \multirow{3}{*}{$\begin{array}{l}\text { Aditiva } \\
\text { (Primeira mensagem em um fluxo } \\
\text { discursivo - mensagem } \\
\text { geradora) }\end{array}$} & $\begin{array}{l}\text { Exposição } \\
\text { simples }\end{array}$ & AIAE & Apresenta novas informações ou a proposta do fórum. \\
\hline & & & Problematizadora & AIAP & Apresenta um problema. \\
\hline & & & Questionamento & AIAQ & Instiga novas questões aos participantes, iniciando um tópico. \\
\hline \multirow{20}{*}{$\begin{array}{l}\text { Interativa } \\
\text { (relaciona } \\
\text {-se com } \\
\text { mensage } \\
\text { m } \\
\text { existente) }\end{array}$} & \multirow{10}{*}{\begin{tabular}{|l} 
Direta \\
(Relaciona-se \\
diretamente com o \\
fluxo de mensagens e \\
tem relação direta \\
com alguma \\
mensagem anterior \\
no mesmo tópico)
\end{tabular}} & \multirow{8}{*}{$\begin{array}{l}\text { Continuidade } \\
\text { (A mensagem contribui para a } \\
\text { continuidade do tópico/ } \\
\text { discussão) }\end{array}$} & $\begin{array}{l}\text { Exposição } \\
\text { simples }\end{array}$ & IDCRe & Tem caráter de resposta simples ou de adição de novas informações. \\
\hline & & & Esclarecimento & IDCEs & Solicita esclarecimento sobre algo que não esteja claro (não compreensão). \\
\hline & & & Explicação & IDCEx & Solicita explicações por alguma informação faltante (falta de informação). \\
\hline & & & Recondução & IDCRc & Reapresenta o tema principal, foco das discussões. \\
\hline & & & Reflexiva & IDCRx & Discute o tema ou mensagem. \\
\hline & & & Questionamento & IDCQ & Instiga questões aos participantes. \\
\hline & & & Problematizadora & IDCP & Discute um problema, contextualizado ou não. \\
\hline & & & Motivacional & IDCM & Estimula e/ ou motiva, os participantes. \\
\hline & & \multirow{2}{*}{$\begin{array}{l}\text { Ruptura } \\
\text { (Encerra a discussão e/ou } \\
\text { direciona para outro foco) }\end{array}$} & Redirecionamento & IDRR & $\begin{array}{l}\text { O redirecionamento da discussão poderá ocorrer de diversos, seja com uma } \\
\text { questão, com uma problematização etc. }\end{array}$ \\
\hline & & & Encerramento & IDRE & Encerra a discussão. \\
\hline & \multirow{10}{*}{$\begin{array}{l}\text { Indireta } \\
\text { (Relaciona-se } \\
\text { indiretamente com } \\
\text { alguma contribuição } \\
\text { de outro tópico, no } \\
\text { mesmo fórum) }\end{array}$} & \multirow{8}{*}{$\begin{array}{l}\text { Continuidade } \\
\text { (A mensagem contribui para a } \\
\text { continuidade do tópico/ } \\
\text { discussão) }\end{array}$} & $\begin{array}{l}\text { Exposição } \\
\text { simples }\end{array}$ & IICRe & Tem caráter de resposta simples ou de adição de novas informações. \\
\hline & & & Esclarecimento & IICEs & Solicita esclarecimento sobre algo (não compreensão). \\
\hline & & & Explicação & IICEx & Solicita explicações por alguma informação faltante (falta de informação). \\
\hline & & & Recondução & IICRc & Representa o tema principal, foco das discussões. \\
\hline & & & Reflexiva & IICRx & Discute o tema ou mensagem. \\
\hline & & & Questionamento & IICQ & Instiga questões aos participantes. \\
\hline & & & Problematizadora & IICP & Discute um problema, contextualizado ou não. \\
\hline & & & Motivacional & IICM & Estimula e/ ou motiva, os participantes.. \\
\hline & & \multirow{2}{*}{$\begin{array}{l}\text { Ruptura } \\
\text { (Encerra a discussão e/ou } \\
\text { direciona para outro foco) }\end{array}$} & Redirecionamento & IIRR & $\begin{array}{l}\text { O redirecionamento da discussão poderá ocorrer de diversos, seja com uma } \\
\text { questão, com uma problematização etc. }\end{array}$ \\
\hline & & & Encerramento & IDRE & Encerra a discussão. \\
\hline Casual & Indiferente & Sem relação & Geral & C & Mensagem fora do foco da discussão. \\
\hline
\end{tabular}

Fonte: Hornink, 2010. 